$\begin{array}{ll} & \text { Etnográfica } \\ \text { etnográfica } & \text { Revista do Centro em Rede de Investigação em }\end{array}$

Antropologia

vol. 20 (1) | 2016

Vol. 20 (1)

\title{
Sentidos do consumo e fronteiras simbólicas: uma etnografia entre grupos de baixa renda em um município da Grande São Paulo, Brasil
}

Senses of consumption and symbolic boundaries: an ethnography of low-income groups in a township of the greater São Paulo, Brazil

\section{Ana Lúcia de Castro}

\section{OpenEdition}

\section{Journals}

\section{Edição electrónica}

URL: https://journals.openedition.org/etnografica/4216

DOI: 10.4000/etnografica.4216

ISSN: 2182-2891

\section{Editora}

Centro em Rede de Investigação em Antropologia

\section{Edição impressa}

Data de publição: 1 fevereiro 2016

Paginação: 101-117

ISSN: 0873-6561

\section{Refêrencia eletrónica}

Ana Lúcia de Castro, «Sentidos do consumo e fronteiras simbólicas: uma etnografia entre grupos de baixa renda em um município da Grande São Paulo, Brasil», Etnográfica [Online], vol. 20 (1) | 2016, posto online no dia 04 março 2016, consultado o 11 fevereiro 2022. URL: http:// journals.openedition.org/etnografica/4216 ; DOI: https://doi.org/10.4000/etnografica.4216

\section{(c) (†) 8}

Etnográfica is licensed under a Creative Commons Attribution-NonCommercial 4.0 International License. 


\section{Sentidos do consumo e fronteiras simbólicas: uma etnografia entre grupos de baixa renda em um município da Grande São Paulo, Brasil}

\section{Ana Lúcia de Castro}

O artigo apresenta uma reflexão acerca dos impactos do acesso ao consumo nas sensibilidades e práticas cotidianas de um novo grupo de consumidores, recentemente constituído no Brasil. Tenta-se compreender em que medida o consumo popular assume diversos sentidos, muitas vezes distantes da busca de distinção e/ou emulação apontada, recorrentemente, pela explicação sociológica. Tomando como chave analítica a dimensão simbólica do consumo, com enfoque na circulação de bens e marcas - associadas a um universo de classe média, seus usos e ressignificações - a etnografia visa compreender as concepções de classe média presentes na percepção de indivíduos pertencentes às classes populares, residentes em um bairro periférico da Grande São Paulo. Interessa-nos, ainda, refletir sobre a maneira como a inclusão deste grupo no mercado de consumo permitiria a esses novos consumidores construírem, ou não, um sentido de pertença a uma suposta "classe média" ou estabelecerem fronteiras simbólicas, tanto interna, como externamente ao grupo.

PALAVRAS-CHAVE: consumo, identificações, distinção social, grupos urbanos, ressignificações simbólicas.

Senses of consumption and symbolic boundaries: an ethnography of low-income groups in a township of the greater São Paulo, Brazil - The article presents a reflection about the impact of having access to consumption in the sensibilities and daily practices of a new group of consumers, recently constituted in Brazil. It attempts to understand to what extent consumption assumes different meanings within this low-income class, at times distant from seeking distinction and/or emulation as pointed out, repeatedly, by sociological explanations. Taking the symbolic dimension of consumption as an analytical key and focusing on the circulation of goods and brands - associated with a middle-class universe, its uses and new meanings -, the ethnography aims to understand the concept of middle-class expressed in the perceptions of individuals belonging to lower classes residing in a suburb of São Paulo. This leads to a reflection on how the inclusion of this group in the consumer market would allow these new consumers to build, or not, a sense of belonging to an alleged "middle-class" or establishing symbolic boundaries, both internally and externally to the group.

KEYWORDS: consumption, identity, social distinction, urban groups, symbolic re-signification.

CASTRO, Ana Lúcia de (castroanalucia75@gmail.com) - Universidade Estadual Paulista - Unesp, Brasil. 


\begin{abstract}
"Os habitantes das ilhas Trobriand são conhecidos por suas enormes pilhas de inhames notavelmente longos e pelas viagens do kula para a troca de braceletes esculpidos em concha, não por seu apego a um funcionalismo estrito. Na maioria das vezes, os pobres são os mais categóricos em afirmar a centralidade do simbólico no consumo. Foram os que viviam nos bairros mais miseráveis da Inglaterra que conservaram o melhor cômodo da casa como um "salão" reservado quase exclusivamente para exibição [...]. Os aldeões camponeses da Índia freqüentemente contraem dívidas não por direitos fundiários básicos, mas para financiar festas de casamento. É a complexidade dos sistemas simbólicos dos povos do mundo, e não um utilitarismo ordinário, que os antropólogos procuram, esperam encontrar e celebrar em seus estudos. Assim, a questão que deveríamos colocar acerca de nossa própria sociedade é se haveria uma estrutura simbólica similarmente rica no âmbito de nossa própria cultura material" (Miller 2004: 27).
\end{abstract}

\title{
INTRODUÇÃO
}

Este artigo desdobra-se como parte de um trabalho de campo que vem sendo desenvolvido em uma área que reúne um conjunto de favelas sob a intervenção das políticas de urbanização de favelas desenvolvidas pela CDHU (Companhia de Desenvolvimento Habitacional Urbano), órgão ligado à Secretaria da Habitação do estado de São Paulo. ${ }^{1}$ Como horizonte analítico, apontamos duas vertentes de discussão: de um lado, volta-se para o estudo dos sentidos do consumo dentre grupos de baixa renda, que em alguns casos escapam à clássica explicação sociológica que aponta para a lógica da imitação-distinção como motivação para o consumo (Bourdieu 2007; Veblen 1983). Por outro lado, o artigo enfoca o estabelecimento, por parte dos residentes entrevistados, de elos de pertença e/ou fronteiras simbólicas em relação à chamada "nova classe média brasileira". No que toca esta última problemática, a etnografia realizada vem apontando para a mudança radical nos modos de morar das famílias "atendidas" pela política habitacional, mudança esta que pressupõe um conjunto de códigos implícitos como regras de convivência, que não foram incorporadas por parte dos moradores, retirados das favelas e reinstalados em prédios de condomínios. Como diretriz analítica geral, que atravessa ambas as vertentes de discussão, coloca-se a busca de se contribuir para a reflexão relativa às fronteiras simbólicas estabelecidas entre as classes e grupos sociais.

Vale lembrar que a vinculação entre consumo e classes populares não era, até bem recentemente, algo comum nas reflexões das ciências sociais, que, via de regra, não vislumbravam a possibilidade de o trabalhador de baixa renda adquirir outros produtos, além dos assim chamados de primeira necessidade.

Duas mudanças concorrem para que esta associação passe a ser colocada na agenda do debate, sendo a primeira de ordem teórica, enquanto a segunda 
diz respeito a mudanças concretas ocorridas na estrutura social brasileira. No que toca à discussão teórica, notamos uma inflexão no debate sobre consumo, a partir do desenvolvimento de uma perspectiva analítica socioantropológica acerca da circulação e apropriação de bens, que se afastava das explicações vigentes, de caráter moralista, e buscava construir uma nova lente para a interpretação do fenômeno, até então analisado por uma visão pautada em dualismos e polarizações. Esta perspectiva, que enfatiza os aspectos simbólicos das trocas e apropriações dos objetos, é caudatária de uma longa tradição, iniciada com Marcel Mauss (2003), em seu clássico Ensaio sobre a Dádiva, passando por Jean Baudrillard (1995), Marshall Sahlins (2003, 2004), Mary Douglas e Baron Isherwood (2004) e, mais recentemente, Arjun Appadurai (2008) e Daniel Miller (2002).

Paralelamente ao transcurso deste debate de cunho teórico, o Brasil veio passando por mudanças em sua estrutura social, produto de políticas de inclusão social, possíveis após a estabilidade econômica propiciada pelo Plano Real. Embora saibamos que não se trata do surgimento de uma "nova classe média", considerando que classe não é uma variável apenas econômica, mas um termo que envolve valores (ethos) e práticas (modos de uso), não é de se desprezar o contingente de pessoas que passaram a ter acesso a bens de consumo considerados "não essenciais", até então excluídas deste mercado. O tema não é consensual e a polêmica nasce da classificação, proposta por alguns intelectuais e técnicos ligados ao governo federal, segundo a qual seriam considerados como pertencentes à classe média os que vivem em famílias com renda per capita mensal entre R\$291,00 e R \$ 1019,00 e têm baixa probabilidade de passar a ser pobres no futuro próximo (Neri 2011).

Não se trata de negar a diminuição da desigualdade social, a redução da concentração da riqueza, a melhoria da renda dos mais pobres e o incremento das perspectivas desse setor da população, mas de questionar este conceito de classe média, que considera a renda como único fator a ser levado em conta. Como aponta Souza (2012), no grupo em questão é importante atentar para a posse de uma certa ética do trabalho, fortemente influenciada por um capital familiar, em que a transmissão de exemplos e valores do trabalho duro e continuado se faz presente, mesmo em condições adversas. Segundo este sociólogo, nos grupos de baixa renda a herança do capital econômico é praticamente nula e o capital cultural é um bem que, ainda que existente, é inferior em relação às elites dominantes; no entanto, a família estruturada é a base que dará sustentação para conquistas de melhores condições de vida e distinção social.

Este contingente de consumidores que vem sendo denominado "nova classe média" é parte das mudanças estruturais que vêm conferindo uma nova conformação à sociedade brasileira, tais como o crescimento da taxa de urbanização (84,3\% em 2010, contra 45,1\% em 1960), a queda na taxa de fecundidade (1,86\% em 2010 e 6,21\% em 1950; cf. Alves e Cavenaghi 2012) e aumento 
do emprego no setor de serviços (57,6\% em 2008 e 22,5\% em 1950; cf. IPEA $2011)$.

Outros dados informam a mudança na pirâmide social. Ainda que totalmente frágil do ponto de vista sociológico, a classificação proposta pelos técnicos do governo federal indica algo novo. Entre 2004 e 2010, 32 milhões de pessoas ascenderam socialmente, ainda que discordemos da denominação, à categoria de classes médias, segundo estudo da Secretaria de Assuntos Estratégicos da Presidência da República (IPEA 2011 ). Por este estudo, estima-se que o Brasil tenha 104 milhões de pessoas na classe média, o que representa 53\% da população brasileira - 20\% estão na classe alta e $28 \%$ na baixa, enquanto, sob o mesmo critério de classificação, apenas $38 \%$ da população estaria na classe média em 2002. ${ }^{2}$

Interessa-nos, nesta reflexão, contribuir para a compreensão acerca do impacto das políticas de inclusão social nas relações entre os grupos ou, em outras palavras, aclarar a discussão relativa à maneira como este contingente de novos consumidores constrói um sentido de pertença e reforça fronteiras simbólicas entre si e em relação às classes médias tradicionais. ${ }^{3}$ Consideramos, neste sentido, contribuir para o mapeamento e compreensão dos diversos sentidos assumidos pelas práticas de consumo dentre esse grupo de novos consumidores.

\section{ESPAÇO ETNOGRÁFICO E CONTORNOS METODOLÓGICOS}

Tomamos como universo empírico o Jardim Santo André, bairro do município de Santo André, Grande São Paulo, onde realizamos observação sistemática dos dois grupos de moradores: os ainda favelados, que habitam em construções precárias, sem infraestrutura urbana, e aqueles moradores dos conjuntos habitacionais entregues pela CDHU, os quais gozam de uma condição social melhorada, por usufruírem de infraestrutura urbana. Em levantamento realizado pela Companhia entre 2009 e 2010 (CDHU 2011), identificaram-se, no bairro, 5799 famílias residentes em núcleos de favelas, caracterizados pela ocupação de propriedade alheia (pública ou particular), dispostas de forma desordenada e densa, carentes, em sua maioria, de serviços públicos essenciais. Deste total, 980 unidades receberam melhorias por processos de urbanização.

O bairro conta, ainda, com 3031 famílias residentes em unidades habitacionais (UH), caracterizadas por conjuntos de prédios (condomínios), produzidos e financiados pela CDHU, em situação regular. Assim, totaliza-se pouco

2 Conforme estudo divulgado em setembro de 2012 pela Secretaria de Assuntos Estratégicos da Presidência da República (AAVV 2012).

3 Para efeitos desta análise, chamamos classes médias tradicionais àqueles grupos que, melhor aparelhados para a competição social, detêm o capital cultural que permite o desenvolvimento de um certo estilo de vida e o cultivo e compartilhamento de um ethos próprio. 
mais de 9000 famílias residentes no local, abrangendo uma população de 28.000 pessoas, em uma gleba de aproximadamente 1,5 milhão de metros quadrados.

A metodologia estatística utilizada para a composição da amostra seguiu os critérios da amostragem casual simples (ACS). O tamanho amostral necessário para uma amostragem casual simples (ACS) é obtido mediante a resolução da seguinte equação:

$$
\mathrm{N}=(\mathrm{Z} \alpha / 2)^{2} \mathrm{p}(\mathrm{l}-\mathrm{p}) / \mathrm{e}^{2}
$$

Onde:

$\mathrm{p}=$ proporção esperada. Adotamos o valor 0,5 por produzir o maior tamanho amostral.

$(\mathrm{Z} \mathrm{\alpha} / 2)^{2}=$ constante correspondente ao intervalo de confiança de $(1-0,05)$ $=1,96$

$\mathrm{e}=$ margem de erro para mais e para menos. Adotamos o valor $=0,05$

Vale ressaltar que o emprego da ACS revelou-se possível pelo fato de se dispor da listagem completa de todos os domicílios das favelas e da unidades habitacionais entregues.

Para minimizar ou mesmo evitar possíveis perdas - domicílio vazio, desocupado ou recusa do entrevistado -, o domicílio sorteado só foi considerado perdido após três visitas em dias alternados da semana. Nessa eventualidade, seu vizinho mais próximo, no sentido horário (o da direita), foi tomado como substituto. Na prática, portanto, trabalhamos uma amostra "substituta" evitando-se eventuais perdas.

Assim, trabalhamos com duas amostragens: a que representa os moradores das favelas é composta por 365 famílias, constituídas por 1340 moradores, e uma segunda, envolvendo 385 famílias e 1449 moradores, representa os moradores em unidades habitacionais entregues pela CDHU.

Vale ressaltar que a área em questão foi adquirida pela CDHU em 1977, como estoque de terras, porém algumas famílias já ocupavam o local de forma irregular. A partir de 1980 a ocupação irregular e desordenada intensificou-se, transformando-a em um dos maiores assentamentos precários em terreno de propriedade da CDHU. No final dos anos 80, a CDHU iniciou um processo de intervenção na área, reassentando as famílias moradoras do Jardim Santo André em novas unidades habitacionais construídas e financiadas pela companhia. Em 1998 muda o caráter da intervenção da CDHU, com a proposta de se introduzir o conceito de urbanização de favelas e não ter sua ação mais reduzida apenas à produção de unidades habitacionais e ampliando-se o campo de preocupação das ações implementadas, que agora deveriam considerar 
também os espaços para prestação de serviços de saúde, escolas e áreas de lazer e convivência.

Uma vez apresentados o espaço etnográfico e os critérios para composição das amostras consideradas no levantamento de dados quantitativos, passemos agora a descrever brevemente as condições socioeconômicas efetivamente encontradas no bairro em estudo, através da análise dos dados quantitativos relativos à escolaridade, renda e itens de consumo, para, num segundo momento, adentrarmos nos dados levantados nas incursões etnográficas realizadas, compostas por observações e entrevistas individuais.

\section{UM BREVE PERFIL DOS MORADORES DO BAIRRO}

É possível afirmar que a população em estudo situa-se na periferia da periferia, tanto do ponto de vista geográfico como social. Buscando comparabilidade com as informações censitárias, apresentamos os dados de escolaridade excluindo as pessoas com menos de 10 anos de idade e, como demonstrado no quadro 1, a escolarização dos moradores nas favelas é mais baixa do que a nacional.

Segundo o último censo, 50,2\% da população brasileira não tinha instrução nenhuma ou contava apenas com o fundamental completo e na mesma situação encontravam-se 59\% e 44,8\% da população do Nordeste e do Sudeste, respectivamente. Como é possível observarmos no quadro 1 , dentre os moradores das favelas o percentual de pessoas nesta condição (62\%) fica acima não só dos dados relativos ao Brasil e ao Sudeste, mas também ao Nordeste, que apresenta o maior contingente de pessoas nesta condição de escolaridade.

Com o fundamental completo e ensino médio incompleto temos 18,3\% da população do Sudeste, conforme o censo, enquanto em nossas amostras o percentual fica em torno de 15\%. Um quarto da população do Sudeste brasileiro concluiu o ensino médio e ingressou no nível superior, mas não o concluiu, segundo o censo. Dentre nossos entrevistados, o percentual nesta condição de escolaridade é ainda mais baixo entre os moradores em favelas $(22,3 \%)$, conforme mostra o mesmo quadro. Os percentuais dos que concluíram o nível superior são 8,3\%; 4,9\%; 10,5\%, para o Brasil, Nordeste e Sudeste, respectivamente, enquanto em nossas amostras são bem menores: 0,7\% (favelas) e 2\% (UH). ${ }^{4}$

O censo também aponta que 24,02\% dos domicílios brasileiros e 15,40\% dos localizados no Sudeste contam com uma renda familiar per capita de até meio salário mínimo, conforme indicado no quadro 2. Em nossas amostras, boa parte de ambos os grupos de famílias (34\% nas UH e 42,5\% nas favelas)

4 Dados censitários disponíveis em < http://censo2010.ibge.gov.br > (última consulta em janeiro de 2016). 
Quadro I

Escolaridade dos moradores com mais de 10 anos de idade

\begin{tabular}{|c|c|c|c|c|c|c|}
\hline \multirow{2}{*}{ Escolaridade } & \multicolumn{3}{|c|}{ Favelas } & \multicolumn{3}{|c|}{ UH } \\
\hline & Frequência & $\%$ & $\%$ acumulada & Frequência & $\%$ & $\%$ acumulada \\
\hline 1. a do fundamental & 16 & 1,5 & 1,5 & 17 & 1,4 & 1,4 \\
\hline 2. a do fundamental & 24 & 2,2 & 3,7 & 22 & 1,9 & 3,3 \\
\hline 3. ${ }^{a}$ do fundamental & 34 & 3,2 & 6,9 & 35 & 2,9 & 6,2 \\
\hline $4 .^{\mathrm{a}}$ do fundamental & 117 & 10,9 & 17,9 & 125 & 10,5 & 16,8 \\
\hline 5. ${ }^{a}$ do fundamental & 138 & 12,9 & 30,7 & 95 & 8,0 & 24,8 \\
\hline 6. ${ }^{\mathrm{a}}$ do fundamental & 90 & 8,4 & 39,2 & 69 & 5,8 & 30,6 \\
\hline 7. a do fundamental & 102 & 9,5 & 48,7 & 74 & 6,2 & 36,8 \\
\hline 8. ${ }^{\mathrm{a}}$ do fundamental & 94 & 8,8 & 57,5 & 90 & 7,6 & 44,4 \\
\hline 9. ${ }^{\mathrm{a}}$ do fundamental & 48 & 4,5 & 62,0 & 59 & 5,0 & 49,4 \\
\hline 1. a do ensino médio & 55 & 5,1 & 67,1 & 65 & 5,5 & 54,8 \\
\hline 2. ${ }^{\mathrm{a}}$ do ensino médio & 63 & 5,9 & 73,0 & 56 & 4,7 & 59,6 \\
\hline 3. ${ }^{\mathrm{a}}$ do ensino médio & 219 & 20,5 & 93,5 & 379 & 31,9 & 91,5 \\
\hline Superior incompleto & 19 & 1,8 & 95,2 & 43 & 3,6 & 95,1 \\
\hline Superior completo & 8 & 0,7 & 96,0 & 24 & 2,0 & 97,1 \\
\hline $\begin{array}{c}\text { Nenhuma, } \\
\text { mas sabe ler e escrever }\end{array}$ & 7 & 0,7 & 96,6 & 9 & 0,8 & 97,9 \\
\hline $\begin{array}{c}\text { Nenhuma, } \\
\text { não sabe ler e escrever }\end{array}$ & 36 & 3,4 & 100,0 & 25 & 2,1 & 100,0 \\
\hline Total & 1070 & 100,0 & & 1187 & 100,0 & \\
\hline
\end{tabular}

Nota: Nas favelas, 270 têm menos de 10 anos; nas unidades habitacionais, 260 têm menos de 10 anos e houve dois casos sem resposta.

conta com um valor de até meio salário mínimo como renda familiar per capita mensal, como pode-se observar no quadro 3. Apresentamos, no quadro 2, os dados relativos à renda familiar per capita para o Brasil e regiões.

O segundo aspecto importante revelado pela análise da renda familiar per capita é evidenciado pela contraposição da mesma com os dados relativos ao consumo familiar mensal, que nos aponta para uma absorção praticamente total das rendas familiares com itens básicos de sobrevivência, resultando na incapacidade de poupança e, consequentemente, no crédito como única alternativa para aquelas famílias que desejam construir perspectivas de futuro. É conhecido o papel do cartão de crédito como instrumento de inserção dos 


\section{Quadro 2}

\section{Rendimento nominal mensal per capita dos domicílios particulares permanentes no Brasil e grandes regiões (2010)}

Classes de rendimento nominal $\%$ de domicílios particulares permanentes

\section{mensal domiciliar per capita}

Até $1 / 8$ de salário mínimo

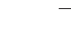

$\begin{array}{rrrrcc}\text { Brasil } & \text { Norte } & \text { Nordeste } & \text { Sudeste } & \text { Sul } & \text { Centro-Oeste } \\ 3,66 & 6,81 & 9,42 & 1,10 & 0,93 & 1,33 \\ 5,12 & 9,41 & 10,39 & 2,70 & 2,23 & 3,02 \\ 15,24 & 21,05 & 23,58 & 11,60 & 9,87 & 13,34 \\ 27,39 & 26,37 & 28,14 & 27,04 & 26,77 & 29,05 \\ 23,49 & 16,37 & 13,51 & 27,44 & 31,25 & 25,43 \\ 8,08 & 5,13 & 3,82 & 9,88 & 11,23 & 8,61 \\ 6,14 & 3,74 & 2,97 & 7,63 & 8,00 & 6,84 \\ 4,23 & 2,48 & 2,09 & 5,38 & 4,92 & 5,13 \\ 2,22 & 1,13 & 1,07 & 2,92 & 2,22 & 3,15 \\ 4,42 & 7,50 & 5,01 & 4,30 & 2,58 & 4,09\end{array}$

Notas: 1 - Dados da amostra. 2 - Salário mínimo utilizado: R\$ 510,00. 3 - A categoria "Sem rendimento" inclui as informações dos domicílios com rendimento somente em benefícios. Fonte: IBGE - Censo Demográfico 2010.

\section{Quadro 3}

\section{Rendimento familiar per capita em salários mínimos}

\begin{tabular}{|c|c|c|c|c|c|c|}
\hline \multirow{2}{*}{$\begin{array}{c}\text { Faixa } \\
\text { de rendimento }\end{array}$} & \multicolumn{3}{|c|}{ Favelas } & \multicolumn{3}{|c|}{ UH } \\
\hline & Frequência & $\%$ & $\%$ acumulada & Frequência & $\%$ & $\%$ acumulada \\
\hline Sem Rendimento & 10 & 2,7 & 2,7 & 2 & 0,5 & 0,5 \\
\hline $\begin{array}{c}\text { Até } \mathrm{l} / 4 \text { de salário } \\
\text { mínimo }\end{array}$ & 42 & 11,5 & 14,2 & 21 & 5,5 & 6,0 \\
\hline $\begin{array}{c}\text { De } 1 / 4 \text { a } 1 / 2 \\
\text { salário mínimo }\end{array}$ & 103 & 28,2 & 42,5 & 108 & 28,1 & 34,0 \\
\hline $\begin{array}{c}\text { De } 1 / 2 \text { a } 1 \\
\text { salário mínimo }\end{array}$ & 151 & 41,4 & 83,8 & 148 & 38,4 & 72,5 \\
\hline $\begin{array}{c}\text { De } 1 \text { a } 2 \\
\text { salários mínimos }\end{array}$ & 54 & 14,8 & 98,6 & 89 & 23,1 & 95,6 \\
\hline $\begin{array}{c}\text { De } 2 \text { a } 3 \\
\text { salários mínimos }\end{array}$ & 3 & 0,8 & 99,5 & 15 & 3,9 & 99,5 \\
\hline $\begin{array}{c}\text { Acima de } 3 \\
\text { salários mínimos }\end{array}$ & 2 & 0,5 & 100,0 & 2 & 0,5 & 100,0 \\
\hline Total & 365 & 100,0 & & 385 & 100,0 & \\
\hline
\end{tabular}


grupos de baixa renda no mercado de consumo, garantindo aos "pobres" o acesso a bens de consumo e gerando a "financeirização" dos orçamentos domésticos, com os empréstimos e contrapréstimos. Esta dinâmica alimenta a lógica da dívida, acionando o mecanismo de se pagar dívidas com outras dívidas (Sciré 2012).

Quanto às formas de dispêndio, vale ressaltar que a maior parte da renda das famílias entrevistadas - tanto moradoras nas favelas como nas UH - é despendida com alimentação, pois praticamente metade delas gastam um valor entre $\mathrm{R} \$ 300,00$ e R $\$ 600,00$ com despesas alimentares. O perfil de consumo das famílias residentes em unidades habitacionais reforça a sutil diferença, já verificada, na condição socioeconômica de ambos os grupos estudados. Assim como no grupo das famílias faveladas, a alimentação é o item que mais absorve a renda das famílias, seguido de vestuário; contudo, observa-se, nas famílias residentes em UH, uma maior concentração nas faixas de gastos mais elevadas.

Nas favelas temos algo em torno de $60 \%$ do total das famílias declarando ter algum tipo de despesa mensal para atender à necessidade de vestir-se; dentre elas, aproximadamente 97\% afirmam despender até R\$200,00 mensais com roupas, havendo $67 \%$ que gastam o valor de até R \$50,00 com este item, enquanto nas UH o percentual de famílias despendendo com vestuário nesta faixa é de apenas 32,8\%. Em contrapartida, ao observarmos a faixa entre R \$ 200,00 a R \$ 400,00 percebemos o inverso: uma maior concentração das famílias residentes nas UH ( $11,2 \%)$, enquanto apenas 3,7\% das famílias faveladas declaram despender esta faixa de valores com vestuário. ${ }^{5}$

O mesmo padrão é percebido com relação aos gastos com saúde, educação e lazer. Maiores concentrações de famílias das favelas declaram gastos menores com estes itens de despesa, enquanto maiores percentuais de famílias das $\mathrm{UH}$ declaram despender maiores volumes de recursos com os mesmos. A saúde aparece como item de despesa mensal para 40,8\% do total de famílias faveladas e $43 \%$ das moradoras em UH. Dentre as famílias moradoras em favelas que afirmam ter este tipo de gasto regularmente, $81,2 \%$ despendem até R\$200,00 com o item, das quais 29\% declaram despender até R $\$ 50,00$ e $22,8 \%$ entre R\$ 100,00 e R\$200,00. Dentre os moradores em UH, 83,3\% despendem até R\$ 200,00 com o item saúde, porém somente 19\% despendem até R\$50,00 e 36,4\% investem um valor correspondente à faixa de $\mathrm{R} \$ 200,00$ a $\mathrm{R} \$ 300,00$ em saúde.

Dentre as famílias faveladas que declaram ter algum tipo de despesa com lazer, 91\% afirmam despender até R\$200,00 mensais, das quais 34\% despendem até $R \$ 50,00$ e 20,5\% entre $R \$ 100,00$ e $R \$ 200,00$, enquanto dentre as

5 Vale esclarecer que estes dados, relativos às faixas de dispêndio com cada item de despesa, foram coletados através de uma questão de "múltipla escolha" e, portanto, não totalizam 100\% de respostas, pois a mesma família aponta diferentes itens de despesa em cada faixa de recursos despendidos. 
famílias das UH, apenas $15 \%$ despendem até R\$ 50,00 e 28,8\% despendem algo entre R\$ 100,00 e R \$200,00 mensais com lazer.

Dentre as famílias que afirmam ter gastos regulares com educação, 86,7\% das famílias residentes em favelas declaram gastar a quantia mensal de até R\$200,00, ao passo que dentre o grupo residente nas UH apenas $40 \%$ declaram despender até este valor com educação. Mais uma vez, nas faixas de gastos mais altos o padrão é mantido e aparecem maiores proporções de famílias das UH em relação às faveladas.

Gás, energia elétrica e água são itens de despesa mensais para boa parte das famílias que compõem a amostra, respectivamente: 96\%, 81\% e $57 \%$ para as famílias faveladas. Contudo, para quase a totalidade das famílias faveladas que gastam com estes itens de consumo, os valores absorvidos ficam na faixa de até $R \$ 50,00$, com exceção da energia elétrica que, um pouco mais cara, absorve até R\$ 100,00 de 91,4\% das famílias que despendem com este item. Para $71,1 \%$ das famílias residentes em UH a energia elétrica consome até $\mathrm{R} \$ 100,00$ e a faixa de gasto entre $\mathrm{R} \$ 100,00$ e $\mathrm{R} \$ 200,00$ envolve $27,5 \%$ das mesmas, enquanto apenas $7,8 \%$ das famílias faveladas declaram esta faixa de gasto com este item de despesa. ${ }^{6}$

Despesas com telefone são regulares para $68,7 \%$ das famílias moradoras nas favelas e $62,9 \%$ daquelas que ocupam as $\mathrm{UH}$, dentre as quais $92,5 \%$ e $81,9 \%$, respectivamente, declaram gastar até $\mathrm{R} \$ 100,00$.

As despesas com transporte e locomoção ocupam importante lugar no ranking de itens de consumo: $52,7 \%$ do total da amostra de famílias residentes na favela e 61,5\% das famílias que representam os moradores das UH afirmam ter este tipo de despesa mensal e a grande maioria das famílias de ambas as amostras despendem até $\mathrm{R} \$ 200,00$ ao mês com este tipo de gasto.

Em suma, estes dados nos indicam, de modo geral, que estas famílias vivem no limiar da subsistência, com a quase totalidade de seu orçamento comprometido com itens básicos de sobrevivência. Contudo, uma simples caminhada pelo local nos revela que o consumo destas famílias não se resume aos chamados bens de primeira necessidade. Buscando compreender melhor este dado, intensificamos o trabalho de campo e percebemos a circulação de bens e produtos associados ao universo das grifes, o que nos apontou outros aspectos da discussão em pauta e nos levou à necessidade de empreender outros percursos analíticos, decorrentes da busca de se construir um mapeamento dos sentidos do consumo dentre este grupo de baixa renda.

6 Vale lembrar que boa parte das famílias que habitam as favelas contam com instalações clandestinas de água e energia elétrica, conhecidas como "gatos" e, portanto, não pagam pelo fornecimento do serviço. 


\section{SENTIDOS DO CONSUMO E FRONTEIRAS SIMBÓLICAS}

A proposição desta experiência etnográfica, que prevê o "encontro empático" com os consumidores, busca, de um lado, contribuir ao esforço de restituir a dimensão cultural de nossa sociedade, em geral tratada apenas como economia (Appadurai 2008), numa abordagem da cultura material por meio das nuanças da imersão etnográfica, tal como desenvolvida por Miller (2002), e, de outro lado, pretende colaborar na construção de uma perspectiva analítica que alargue a corriqueira continuidade das obras de Veblen (1983) e Bourdieu (2007), tão presente nas ciências sociais, ora tomando-se exemplos extremos de consumo conspícuo como caracterização de todo e qualquer consumo, ora indicando-se a instrumentalização de bens de consumo nas estratégias de distinção.

Foram realizadas várias incursões etnográficas no período de julho de 2014 a maio de 2015, nas quais realizamos observações e entrevistas individuais. Nestas incursões, saltaram-nos aos olhos os varais improvisados com camisetas estampando grifes conhecidas. Em um mesmo quintal de "terra batida", é possível flagrar criação de galinhas e um adolescente portando um boné de marca renomada e cobiçada pelos jovens. Um outro aspecto que nos chamou a atenção, nessas primeiras observações, refere-se ao fato de que, embora bastante isolados e com precariedade material extrema (em alguns casos há uma distância de $3 \mathrm{~km}$ até o ponto de ônibus mais próximo, ruas sem asfaltamento, habitações em piso de terra batida, ausência ou improvisação de mobiliário), os moradores do local contam com um grande número de "salões de beleza", invariavelmente com os dizeres inscritos em uma placa improvisada, em madeirite ou papelão, que sobraram como refugos da autoconstrução.

Caminhando pelas ruas, becos e vielas do bairro, nos deparamos com realidades muito diversas. Em uma rua em que a intervenção da CDHU é mais antiga, as casinhas entregues no início dos anos 90 e já quitadas passaram por ampliações e reformas, algumas delas contando agora com garagens para três carros, portóes com altas grades de ferro, calçada e quintais pavimentados, pintura externa; três ruas abaixo, numa ocupação irregular, próxima a um córrego por onde passa um esgoto a céu aberto, avistamos barracões construídos com materiais improvisados, quintais de terra batida com criações de galinhas.

A ausência de supermercados próximos é suprida por vários pequenos pontos comerciais, com venda de produtos básicos, como arroz, feijão, óleo e material de limpeza, que contam sempre com um balcão onde se serve a "branquinha". ${ }^{7}$

Ao avistar uma longa fila logo descubro que se trata de distribuição de uma "cesta básica", composta por arroz, feijão, óleo e um cacho de banana. O local da distribuição é a Associação de Moradores e a pessoa que organiza é Célia, ${ }^{8}$

7 Nome atribuído pelos moradores à cachaça.

8 Todos os informantes receberam nomes fictícios. 
que depois se demonstrou liderança e figura histórica no local e é proprietária da casa ao lado do galpão que abriga a Associação. Inicio uma conversa com ela, que pede para marcar para um outro dia, pois está naquele momento muito ocupada no atendimento às pessoas. Numa segunda visita, realizo uma entrevista, na qual ela conta que mudou para o bairro há 27 anos, quando integrava um grupo que realizou as primeiras ocupações no local. Seu papel de liderança vai se evidenciando no decorrer da entrevista e ela relata que concorreu a vereadora na última eleição, mas não foi eleita. É curioso percebermos como este perfil de liderança local está ligado à ação dos técnicos sociais da CDHU que lá atuaram.

"É uma história até legal. A construção foi em 97, logo que as meninas da $\mathrm{CDHU}^{9}$ vieram pra Santo André... E pediam para acompanhar elas pra entregar uns panfletos... até aí eu não tinha muito vínculo com a minha comunidade... meu vínculo ainda estava com a outra comunidade que eu morava - que era o Jd. Cristiane. Aí, comecei a andar com o pessoal do social da CDHU, daí começou a criar uma relação estreita com as famílias, comecei a ver as necessidades, a violência".

E quanto à criação do galpão que abriga a Associação de moradores, relata:

“Daí, até a assistente social falou 'vamos abrir uma associação', que na época não tinha, só tinha de futebol, mas uma coisa bem fechada, bem individual. E a gente abriu a associação, depois de muitos anos, e começamos a ajudar a comunidade. Começamos com uma casa caindo aos pedaços, fomos para um barracão e hoje estamos aqui".

A diferença sentida em sua vida e na dos seus vizinhos é expressa na fala de Célia pela ênfase em uma grande melhora, tanto das condições de vida, como das oportunidades que se colocam. Quando solicitada a falar mais um pouco sobre as mudanças que ela percebia na vida das pessoas do local desde a chegada das técnicas da CDHU, ela afirma:

"Nossa! Mudou a visão, a atitude... um processo muito bom que eles passaram. A urbanização... hoje já não falam mais comunidade, falam bairro. Tem direito a escola, a estudar, a fazer faculdade. E também a troca, né: se tenho direito também tenho deveres. Eles começaram a ter essa visão que não tinham.

9 A entrevistada se refere na entrevista às técnicas da área social da CDHU como "meninas da CDHU”. 
[...] O governo federal ajuda bastante também... vou dizer até 2010 com a bolsa família, essas coisas. Só que eu acho que é pouco. Acho que a maior participação com a mudança de direitos e deveres foi a CDHU. As técnicas... o trabalho delas, 'olha isso daqui está certo, isso está errado'”.

Mas, a despeito de reconhecer a grande melhora sentida nas condições de vida no local, Célia insiste que ainda há muito a fazer, lembrando dos projetos inacabados que ficaram paralisados no passado...

"Hoje todo mundo tão comendo melhor. Morando melhor... acho que algumas tão devendo ainda... a CDHU, precisa melhorar mais. Tem muita coisa malfeita pra trás que precisa ser revista. Mas em vista do que era, tá bom, mas dá pra ficar melhor... é preciso mais renda, mais trabalho, mais cursos profissionalizantes, porque com a CDHU a gente conseguiu bastante cursos profissionalizantes, com a prefeitura".

Quando questionada se poderíamos dizer que as pessoas do bairro agora eram de classe média, percebemos que a visão economicista defendida pelo governo federal penetrou no discurso da entrevistada:

“Agora essas pessoa tudo pode dizer que são da classe média... O poder aquisitivo delas tão melhor e a questão da moradia... temos um grupo mínimo que vive numa moradia indigna, sub-humano... mas a maioria já se sente da classe média... com certeza. Posso te garantir. Temos pessoas fazendo faculdade... já é uma coisa de outro mundo. Cursos... eles se sentem sim. Pelo jeito, modo de falar. As vezes eu até brinco, 'eita, pagando, né'. Poder aquisitivo grande".

Tentando explorar melhor a relação com a sua visão sobre a classe média, insisti na pergunta sobre o que diferencia a classe média dos pobres, e a entrevistada aponta a ideia de oportunidade:

"Acho assim: é o poder aquisitivo que temos, uma boa moradia... eu não digo que é pobre, é que não teve uma oportunidade... não ter tido oportunidade de ter uma moradia, de ter um curso profissionalizante, de ter estudo, isso faz com que eles tenham uma precariedade tremenda, sabe, e não tem como... como eu sobrevivo a esse mundo... a esse país, se eu não tenho apoio do poder público".

É interessante perceber que, no que se refere à aquisição de bens materiais, embora no plano discursivo apareça a ideia de que sentem-se incluídos num universo social ao qual antes não pertenciam, identificado como classe média, 
quando observamos as apropriações destes bens como forma de "parecer" com as pessoas identificadas como pertencentes à classe média, notamos a negação do desejo de pertencer ou parecer com ela, geralmente associada a uma imagem negativa. Esta direção na análise, relativa ao não desejo de pertença à classe média, surgiu no decorrer de uma entrevista realizada com Mara, ajudante de cozinha, que ao ser perguntada se frequenta a "feira da madrugada" 10 para comprar produtos de grife para se parecer com a classe média, respondeu: "Não, não quero ser esnobe como eles, nem metida, eu compro porque dura mais..."

Na mesma linha, Nora, recepcionista, afirma: "Compro roupas de marca porque percebi que sou melhor aceita no meu trabalho, mas não quero ser como a classe média que fica disputando quem compra a roupa mais cara..."

Ao se referir aos bazares beneficentes que organiza no galpão da Associação, quando comercializa produtos doados, muitos dos quais roupas de marcas consagradas, como Zara e Fórum, Célia descreve os desfiles irônicos em que alguns ridicularizam personagens da televisão, imitando-as de maneira debochada.

Evidencia-se então que, quando a questão é a apropriação de bens para imitação, visando passar por, ser identificado como classe média, aparece uma noção negativada de classe média, expressa, também, nos dizeres de Sonia, empregada doméstica que, ao se referir à sua patroa, diz: "tenho pena dela, sabe... ela só come alface, só usa preto... deve ser muito triste..." Contudo, quando o que está em pauta é o pertencimento à classe média pela inclusão via políticas públicas, a ideia de pertença é positivada e desejada.

Foram diversas as situações de campo, entre relatos e observações, que apontaram para a ideia de que as práticas de consumo, dentre este grupo de baixa renda, não têm necessariamente o sentido de imitar a classe média ou denotar distinção social, mas também de acessar este universo alheio, circular por ele - brincando e ironizando - e permanecer no seu próprio, do qual extraem prazer e ao qual expressam, algumas vezes, orgulho de pertencer. A lógica da imitação-distinção não é o que, exclusivamente, orienta o grupo em suas práticas de consumo, que a conhece e joga/brinca com ela. Isto pode trazer uma importante implicação para a teoria socioantropológica, pois revela que os indivíduos não apenas reproduzem a lógica que orienta a sociedade, mas dela se apropriam e a ressignificam em suas relações cotidianas.

Ao pensarmos a apropriação dos bens de consumo, sobretudo os ligados ao universo das grifes e das celebridades, é possível sugerir, metaforicamente, que as fronteiras simbólicas que reafirmam a distinção social são reconhecidas e constantemente reforçadas por aqueles que se esforçam para afastar-se dos

10 Feira de produtos importados, em grande parte de origem ilegal, que ocorre clandestinamente em algumas noites de alguns finais de semana. A divulgação da feira ocorre discretamente, na "boca a boca", para que não haja intervenção policial. 
"de baixo", os quais, por sua vez, conhecem os códigos suficientemente para deles se apropriarem, atravessarem a fronteira, "passear pelo outro lado" e retornarem.

Vale salientar que essas situações - em que ocorre apropriação dos bens de consumo com motivações que escapam da lógica da imitação-distinção - são verificadas entre os grupos de baixa renda que se aproximam daquele grupo denominado por Souza (2012) como "batalhadores brasileiros", ou seja, trabalhadores que se diferenciam dos "de baixo" - denominados pelo autor como "ralé" - por contarem com rendimentos fixos, embora baixos, e, sobretudo, com família estruturada, transmissora de valores, como o de que estudar e trabalhar duro traz recompensas. Esta classe de batalhadores identifica e ressignifica os bens de consumo como signos de distinção e se apropria deles, em alguns casos orientada por um ethos da necessidade, próprio das classes populares, como coloca Bourdieu (2007). Em outras palavras, este grupo de indivíduos é aquele do qual a classe média busca distinguir-se, mas eles mesmos não reproduzem, necessariamente, esta lógica da imitação-distinção. Em algumas situações brincam, ironizam e até a ridicularizam, enquanto em outras dela se utilizam, em geral com a finalidade de atender a uma necessidade prática, como ser melhor aceito no ambiente de trabalho.

Contudo, ao enfocarmos o grupo de trabalhadores mais precarizados, que não contam com fonte fixa de renda e pertencem a famílias desestruturadas, a fronteira simbólica estabelecida entre as classes sociais apresenta-se como intransponível. Os bens de consumo marcadores de distinção social não fazem parte do repertório e não se colocam como objeto de desejo. A luta diária é pela garantia da próxima refeição e a mudança da condição social excluída e precarizada coloca-se como inalcançável, frente às limitações intransponíveis impostas pela sua origem social. Trata-se daqueles denominados como "ralé estrutural" por Souza (2012: 25), ou daquela classe de indivíduos não só sem capital cultural nem econômico em qualquer medida significativa, mas desprovida, esse é o aspecto fundamental, das precondições sociais, morais e culturais que permitem essa apropriação. Nesses casos, quando exige-se o compartilhamento de um outro ethos bem como de uma outra visão de mundo, esbarra-se numa espécie de desprovimento essencial, fruto de uma limitação socialmente imposta.

Dentre as várias acepções que o termo ethos vem assumindo na reflexão das ciências sociais, cabe destacar a definição proposta por Geertz, pelo seu alcance frente aos desafios desta pesquisa: "O ethos de um povo é o tom, o caráter, a qualidade de sua vida, seu estilo moral e estético e sua disposição, é atitude subjacente em relação a ele mesmo e ao seu mundo que a vida reflete" (Geertz 1989: 144, grifos nossos). Vale salientar que a noção de ethos é constitutiva da epistemologia representada pela sociologia weberiana, na qual se apoia não só Geertz, como também, em boa medida, Pierre Bourdieu. 
Especialmente em sua obra sobre a distinção, Bourdieu (2007) provoca uma redefinição no debate sobre desigualdade social, ao enfocar, ao lado da dimensão econômica, a dimensão cultural, com a formulação do conceito de capital cultural em articulação com o de habitus, entendido como formatador do conjunto de disposições duráveis, estrutura classificadora e classificatória, que orienta as práticas e as percepções dos indivíduos. Nas palavras do autor, o habitus constitui-se em "estrutura estruturante que organiza as práticas e a percepção das práticas, o habitus é também estrutura estruturada; o princípio da divisão das classes lógicas que organiza a percepção do mundo social, é por sua vez o produto da incorporação da divisão em classes sociais" (Bourdieu 2007: 164).

Os relatos das trajetórias de algumas famílias estudadas nos indicam que a passagem da vida na favela para a vida em condomínio não ocorre de maneira homogênea, frente à existência de diversos habitus em convivência. A adaptação maior ou menor aos incômodos e benefícios próprios ao novo modo de habitar está ligada à origem e ao percurso transcorrido, aos encontros e desencontros com empregadores e órgãos públicos, que teriam, de certo modo, desempenhado papel "educativo", propiciando a aquisição de capital cultural e fornecendo ou não a chave de acesso a esse universo, estranho ao seu originário. No caso do grupo mais precarizado, ocorre uma certa transposição para o condomínio dos modos de ocupação do espaço tal qual operados na favela (cachorros soltos, varais no primeiro andar, pequenos comércios com produtos expostos nas janelas, lixo sendo atirado pela janela, audição de música em alto volume), contrariando a expectativa do outro grupo, que embora também "ex-favelado", é constituído pelas famílias mais estruturadas, conta com fonte de renda fixa e, de alguma maneira, incorporou as regras de etiqueta que envolvem a vida em condomínio (ordem, limpeza, discrição).

Por fim, notamos que, embora estejam em condições de igualdade para recomeçar a vida, ou seja, usufruam de uma mesma política pública que possibilita estarem preservados das intempéries naturais - morando em apartamentos com divisão adequada de cômodos e acabamento íntegro, com infraestrutura de água e luz, asfalto e transporte público -, algumas famílias percebem esta condição como uma oportunidade de mudar de patamar em sua luta pela conquista de um suposto melhor lugar social, enquanto outras não detêm o capital social (Bourdieu 2007) necessário para transpor o olhar para além das dificuldades encontradas no presente. Esta diferença tão marcante nas formas de apropriação dos recursos disponibilizados pela política habitacional, bem como na elaboração de projetos futuros, é um dos mais significativos divisores de água no grupo de baixa renda enfocado neste estudo, demarcando uma importante fronteira simbólica interna ao mesmo. 


\section{BIBLIOGRAFIA}

AAVV, 2012, Vozes da Classe Média: É Ouvindo a População Que Se Constroem Políticas Públicas Adequadas. Brasília, Marco Zero/Secretaria de Assuntos Estratégicos da Presidência da República, disponível em < www.sae.gov.br/wp-content/uploads/Cartilha-Vozes-ClasseMedia.pdf > (última consulta em janeiro de 2016).

ALVES, José Eustáquio Diniz, e Suzana CAVENAGHI, 2012, "Tendências demográficas, dos domicílios e das famílias no Brasil”, disponível em < http://www.ie.ufrj.br/ aparte/pdfs/tendencias_demograficas_e_de_familia_24ago 12.pdf $>$ (última consulta em janeiro de 2016).

APPADURAI, Arjun, 2008, A Vida Social das Coisas: As Mercadorias sob Uma Perspectiva Cultural. Niterói, EdUFF - Editora da Universidade Federal Fulminense

BAUDRILlarD, Jean, 1995, Sociedade de Consumo. Lisboa, Edições 70.

BOURDIEU, Pierre, 2007, A Distinção: Crítica Social do Julgamento. São Paulo, Editora da USP; Porto Alegre, Zouk.

CDHU - Companhia do Desenvolvimento Habitacional e Urbano, 201 1, Relatório Jardim Santo André: Atuação da CDHU nas Áreas de Risco. São Paulo, mimeo.

DOUGlas, Mary, e Baron ISHERWOOD, 2004, O Mundo dos Bens: Para Uma Antropologia do Consumo, Rio de Janeiro, Editora da UFRJ.

GEERTZ, Clifford, 1989, A Interpretação das Culturas. Rio de Janeiro, LTC Editora.

IPEA - Instituto de Pesquisa Econômica Aplicada, 201 1, "Natureza e dinâmica das mudanças recentes na renda e na estrutura ocupacional brasileiras", s. l., Instituto de Pesquisa Econômica Aplicada, Secretaria de Assuntos Estratégicos da Presidência da República, Comunicados IPEA, n. ${ }^{\circ}$ 104, disponível em < http://www.ipea.gov.br/portal/images/stories/PDFs/comunicado/110804_comunicadoipea 104.pdf > (última consulta em janeiro de 2016).

MAUSS, Marcel, 2003, "Ensaio sobre a dádiva: forma e razão da troca nas sociedades arcaicas”, em M. Mauss, Sociologia e Antropologia. São Paulo, Cosac Naify, 185-314.

MILlER, Daniel, 2002, Teoria das Compras: O Que Orienta as Escolhas dos Consumidores. São Paulo, Nobel.

MILlER, Daniel, 2004, "Pobreza da moralidade", Antropolitica: Revista Contemporânea de Antropologia e Ciência Política, 17: 21-43, disponível em < http://www.uff.br/antropolitica/revistasantropoliticas/revista_antropolitica_17.pdf $>$ (última consulta em janeiro de 2016).

NERI, Marcelo, 201 1, A Nova Classe Média: O Lado Brilhante da Base da Pirâmide. São Paulo, Saraiva.

SAHLINS, Marshall, 2003, Cultura e Razão Prática. Rio de Janeiro, Jorge Zahar Editor.

SAHLINS, Marshall, 2004, Cultura na Prática. Rio de Janeiro, Editora da UFRJ.

SCIRÉ, Cláudia, 2012, Consumo Popular e Fluxos Globais: Práticas e Artefatos na Interface entre a Riqueza e a Pobreza. São Paulo, AnnaBlume Editora/FAPESP.

SOUZA, Jessé, 2012, Os Batalhadores Brasileiros: Nova Classe Média ou Nova Classe Trabalhadora? Belo Horizonte, Editora UFMG.

VEBlen, Torsten, 1983, A Teoria da Classe Ociosa: Um Estudo Econômico das Instituições. São Paulo, Abril Cultural. 